$\mathrm{PhD}$ in Humanities, Senior Lecturer, DOROTA JANKOWSKA

The Maria Grzegorzewska University in Warsaw Address: 40 Szczesliwiska St., Warsaw, 02-353, Poland

E-mail: kjando@wp.pl

\title{
EDUCATING EDUCATORS AND TEACHERS IN POLAND UNDER CONDITIONS OF NEO-LIBERAL CULTURE OF CONSUMPTION
}

\begin{abstract}
The presented text discusses the problems of academic and teacher education under conditions of consumption culture and neoliberal ideology development at the beginning of the 21st century in Poland. The article puts the thesis that neo-liberalism, manifested by economic phenomena, permeates all spheres of social life, enhancing the characteristics of consumption culture. It enters education, including academic education. In this context, there has been shown a part of our research conducted in 2006-2016 (27 interviews in depth with students completing Master's degree in Pedagogy). The research has taken the form of semantic reconstruction of statements made on studies and pedagogical training, expressed by students during in-depth interviews (IDI). During the research study the leading categories have been defined, which set the main perspectives for thinking about study. Within these perspectives, the student's goals of study have been identified and more detailed profiles of perceiving pedagogical studies have been defined. The comparative analysis of the IDI narratives of 2006 and 2016 allows us to see phenomena that can be interpreted as indicating that pedagogy students are increasingly taking over the market thinking, acting more explicitly as customers of educational services, presenting a utilitarian attitude to study.
\end{abstract}

Keywords: academic education, consumption culture, neo-liberal ideology, pedagogical studies, students.

\section{INTRODUCTION}

Contemporary world has reached an impressive level of scientific and technical development. At the same time, the representatives of social sciences and humanists express their concern about future of our civilization. They point to the continued existence of risk of global war, the danger of ecological or economic catastrophes, the rise of racial, religious or cultural mass conflicts. They indicate that as a result of globalization processes and the uniformity of mass culture, poverty is becoming less and less of cultural diversity. Challenges of modern times escalate the problems and existential dilemmas, placing disoriented people in new situations and forcing them to make difficult and risky choices (Giddens, 2001), hindering the process of shaping one's own identity (Bauman, 1999) and of "reinventing ourselves" (Rorty, 2000, p. 146).

The victory of consumerism and the concomitant idea of pleasure (Baudrillard, 2006) determined the definition of contemporary culture as a culture of consumption (Bauman, 2007; 2009). In culture of consumption reflective lifestyle disappears because as Z. Melosik $(2004$, p. 74$)$ states, "the ideology of consumption, the ideology of pleasure, the coercion of life in an instant moment - all cause the existential questions to cease to make 
sense." Young generations do not seek the meaning of life, rather they turn to small, everyday things, small (and greater) pleasures that can be acquired and consumed. This consumer lifestyle is proposed to them by ubiquitous advertising and they capture the experience of being in virtual reality created by the media.

The culture of consumption in Poland is also being strengthened by the neo-liberal ideology that predominates over earlier liberalism. Many scholars emphasize the differences between these ideologies. J. Rutkowiak (2009) describes them briefly, "unlike liberalism, which exposes the role of freedom in the functioning of societies and individuals, the characteristics of neo-liberalism are the conception of dominance of today's dynamic transnational corporations as organizations of production and distribution of goods and services, organizations gaining prerogatives with particular ruthlessness and cunning and also camouflaging the responsible aspects of their activities (p. 18). Corporate giants have at their disposal world-wide, virtual capital, profit and broaden their economic and economy influence as well as broader non-economic spheres of culture, particularly significant in the sphere of politics. The ideology of neo-liberalism raises competitive sentiment - the fight for success (expressed economically) and interest in profit, which is the main value - makes it possible to belong to a group of privileged possessors-consumers. Under these conditions, the spirit of social solidarity disappears as well as the weakening and the instrumentalization of interpersonal relations takes place. Neoliberalism, which manifests itself in economic phenomena, penetrates all areas of social life, enhancing the characteristics of the culture of consumption. It also penetrates into education, including academic education.

Neo-liberal economy effectively deals with the quality of people (for its own interests). It is about educating the desirable and useful employees of the corporate economy. This is not only mentioned by pedagogues traditionally included in critical pedagogy (P. Freire, H. Giroux, I. Illich, P. McLaren, continuators of the Frankfurt School and J. Habermas (1999)), though they are probably the leaders of this kind of thinking. In Poland, the reference to different degrees of critical thinking and pointing to integration of education into the mechanisms of politics and power is mentioned by M. CzerepaniakWalczak, R. Kwaśnica, Z. Kwieciński, M. Nowak-Dziemianowicz, E. Potulicka, J. Rutkowiak, B. Śliwerski, T. Szkudlarek et al.

\section{THEORETICAL FRAMEWORK AND RESEARCH METHODS}

The penetration of consumption culture and neo-liberal ideology into the sphere of higher education and teacher education in Poland is revealed in the adopted legal and organizational solutions. The Bologna process has had a great impact on the contemporary shape of higher education. Considering the way it is implemented in Poland, we see that it has become primarily socioeconomic and political initiative and secondarily scientific initiative (Jankowska, 2014, pp. 84-88). Its aim was to educate mobile workers for the European labour market rather than educate the reflective elites. It is worth adding that also the adoption in 2012-2013 of the National Qualification Framework as a basis for the design of training programs strengthened thinking about academic education as a preparation for labour market requirements and bureaucratized the education process. In the context of massive higher education and expansion of consumerism and utilitarianism, the promotion of students' practical preparation (which is understandable) has begun to divert the ideas of educating modern personnel capable of transforming reality and creating new labour market and has led to programmatic minimalism and training of non-critical and adaptive workers for the existing production and consumption systems.

In the context of pedagogical education, it should be emphasized that in Poland pedagogical studies from the beginning of the century have become mass studies conducted 
not only within university faculties but also in small centres, sometimes offering only extramural studies. The volume of pedagogical studies co-influenced the weakness of recruitment and lack of selection for teaching profession (Włoch, 2005, p. 223). The basic criterion for admission to study was just a basic level of successful passing the final secondary school leaving exams in selected subjects (Kautz, 2011, p. 174).

Another and, in the light of today's experience, unfavourable phenomenon was the adoption of two-stage study recommended by the Bologna Process (Regulation of the Minister of Science and Higher Education as of June 13, 2006, on the names of study fields). The advocates of such solution pointed out to: a) achieving vertical and horizontal mobility of studies; b) possibility of changing the discipline of study after the first stage of education and, consequently, the flexible adjustment of one's own professional decisions; c) possibility of obtaining a specific profession adapted to the needs of the market in a short education cycle (Woźnicki, 2008). These values in the case of pedagogical studies are not convincing. Two-stage nature of education in the case of pedagogical and teacher education weakens their forming potential, which is extremely important in the pedagogical profession (forming of teacher personality) and hampers the harmonious organization of the education process. The higher education system, aimed at the quantitative growth of students (increasing the number of students), remained unselectively open to all candidates, including those who decided to continue their studies in pedagogy after obtaining a first degree diploma in another field of science. Applied solutions by universities to create the so-called "compensation modules", according to the critics, are far from enough to shape the future educator's personality. On the other hand, those students who continued on the second level of pedagogical studies complained about repetitive content and lack of professional development.

The decline of the prestige of studies has become a significant phenomenon, which is a consequence of the adopted strategy of egalitarianism and the mass character of academic education. Completing the course of study has ceased to guarantee good work. The youths who started their studies in the second decade of the 21 st century, while remaining being influenced by ideology of neo-liberalism, demonstrate expectations of a customer who came to the university as an institution providing educational services. They want to become qualified and enter the labour market effectively and without unnecessary effort (without "unnecessary theories"). At the same time, in the case of pedagogical studies, the market value of their investment is uncertain. The job market is saturated and obtaining a job as a teacher or educator becomes problematic.

How do contemporary students understand the meaning of pedagogical studies and their role in preparing for becoming an educator? Do they feel like customers thanks to whom a university-enterprise can operate?

The question of understanding the studies was the main topic of the author's empirical research, realized within the framework of the project: "Understanding the essence and sense of the academic education process and the role played by the dialogue between the academic teacher and students of public education pedagogy" conducted in 2006-2016. The research took the form of semantic reconstruction of statements made on studies and pedagogical training, expressed by students during in-depth interviews (IDI). The study was based on the transcripts of 15 interviews conducted in 2006 with students of the last semester of the graduate Master's studies ( $10^{\text {th }}$ semester) and 12 interviews in 2016 with the graduates of the second level (fourth semester). All interviews lasted 4 hours on average (2,5 to 5 hours usually during two meetings). The author has conducted them personally according to one scenario, maintaining the same principle of IDI participants 
selection (mail inviting to participate in the interview, total freedom of participation). This allows to treat the material collected in 2016 comparative to that obtained 10 years earlier, and thus allows to track the changes that occurred during that time in the students' understanding of study.

During the research study the leading categories have been defined, which set the main perspectives for thinking about study. They included: 1) scientific knowledge in a particular field, 2) student's own development, 3) work-profession, 4) conducting formal activities. Within these perspectives, the student's goals of study have been identified and more detailed profiles of perceiving pedagogical studies have been defined.

Finally, it was found that the students perceive studies as: 1) a process of pursuing knowledge/truth based on special cognitive motivation, that is, the desire to achieve knowledge (about the world, a man and oneself) as an autotelic value.

Within this perspective, depending on the main goals of study, the following profiles of understanding were distinguished: a) studying as a process of developing humanistic knowledge of man, pointing to their uniqueness and of their culture, helping to understand others, approach them; b) studying as a process of acquiring academic knowledge (at high level), scientific knowledge, making them specialists in the field of studied subject; c) studying as a process of development by learning about oneself, discovering one's abilities and interests.

The profile of study understanding marked with letter "c" has been placed on the boundary between the perspective determined by "knowledge" category and the "student's own development". This latter perspective has been reached by fulfilling the goal of selfdiscovery. However, because the representatives of this idea clearly linked learning with cognitive processes and the most important value for them was knowledge - the localization was determined to be within the first perspective ("knowledge").

2) process of personality development and acquisition of social and cultural experiences based on special motivation for personal growth, for self-fulfilment, achieving professionalism of action.

Within this perspective, depending on the main goals of study, the following profiles of understanding were distinguished: d) studying as a path of self-development primarily happening (though not exclusively) in relation to the learning process; e) studying as developing oneself by gaining social experience, reinforcing courage in fulfilling important tasks and independence of acting (time of study is important and students' activity inspired by studies, but outside the learning process); f) studying as a selfdevelopment through acquisition of experience in the field of activities connected with pedagogical work, also outside formal educational process.

The profile of understanding study, marked with the letter " $\mathrm{f}$ ", aimed at gaining experience in the field of pedagogical activity, entered the field of category 3 professional work. Nevertheless, the starting point was the confusion about studying as a process of personality development rather than preparation for future profession.

3) pursuit of professional development: the development of professional competence and improvement of professional workshop based on the need to be socially useful, capable of working and self-sustaining, and therefore respectable and recognizable.

Within this perspective, depending on the main goals of study, the following profiles of understanding are distinguished: g) studying as a process of acquiring competences needed in the pedagogical profession, developing professional skills and gaining qualifications enabling them to take up professional activity; h) studying as a process of obtaining a higher education diploma, providing a vocational qualification and a means for further career. 
4) the process of seeking for educational success at the higher level based on the need to satisfy ambition, success and prestige, usually (not always) hope for the possibility of obtaining future gratification.

Within this perspective, depending on the main goals of study, the following profiles of understanding are distinguished: i) studying as a continuation of higher education, thereby fulfilling the program designated by the university, fulfilling program obligations, passing examinations, obtaining credits, eventually writing diploma thesis and its defence, resulting in obtaining a certificate/diploma - with the belief that such program implementation raises self-esteem, confirms the capabilities held and raises the level of one's own education; j) studying as a process solely for the purpose of obtaining a higher education diploma as an end in itself, arising from belief that it is worth having it, that it can be a "useful paper" increasing market attractiveness.

\section{RESULTS}

The comparative analysis of the IDI narratives during 2006-2016 allows us to see certain phenomena that can be interpreted as indicating that pedagogy students are increasingly taking over the market thinking, acting more explicitly as customers of educational services, presenting utilitarian attitude to study. In the interviews of 2016, there has been reinforced (in relation to the 2006 statements) the perception of studies in formal terms - obtaining diploma that gives professional qualifications but not combining it with the process of developing humanistic knowledge about a man and his upbringing, which is the weakening factor.

It is difficult in the short form of this article to present with due accuracy the material arguing the above thesis, nevertheless it is possible to try to indicate several related issues.

1. Changes in the field designated by the category "knowledge": the pursuit of knowledge/truth or willingness to consume knowledge/information?

The classical conception of studies as a way of gaining knowledge about the discipline studied and its involvement in the process of its forming, which appeared in the interviews of 2006 (06K5; 06M1; 06K2, 06K9), practically speaking did not occur in 2016. In the article, due to its volume, it was necessary to give up the citation of interviews, hence, only the symbols of interviews were placed in brackets, which picture most prominently the phenomenon described in the text. Symbols contain: the first two digits indicate the year of study: 06-2006, 16-2016, the letter K-woman, M-man and the number of the interviews. So, the students associate the study process not so much with the demanding commitment to knowledge acquisition, but rather its absorption, taking more "consumer" attitude than years ago. Speaking metaphorically, they expect knowledge from their studies: easy-to-digest: clear exemplified and expressed in practice (16K5, 16M1, $16 \mathrm{M} 2)$ and nutritious: utilitarian and pragmatic (16M1, 16K3, 16K6, 167). Placing learning at the service of social needs and popularizing among young people beliefs that only knowledge that has direct (technical) use in practice is valuable reinforced in students of pedagogy the expectations to gain specific information and aversion to any form of theorizing. Certainly, also students graduating in 2006 express special interest in practical knowledge and reluctant attitude to the "dead" theories because they do not explain life, which are "swotted:, especially in the first years of study (06M2, 06K3 06K11, 06K8), nevertheless their criticism is less emotional and more substantive, suggesting changes in the learning process, content layout proposals.

Today's students of pedagogy are less able to switch to didactic and scientific discourse. In interviews with the youths graduating in 2016, there are no threads (still 
present in 2006) devoted to the specifics of language of the studied discipline. Understanding studies is separated from the value of exploring knowledge, embedded in discipline and in closer and closer relationship with thinking about information that is useful in the workplace.

2. Changes in the field designated by the category "student's own development": the pursuit of personality development and the search for ways of self-realization, or the multiplication and collection of experiences documenting personal potential?

Interviews of both 2006 and 2016 indicated that young people starting their studies often do not have a definite vision of their future, hence the duration of their studies has represented and represents a period of self-discovery and looking for their own path of selfdevelopment. The students who graduated from their studies a decade ago while studying under five-year full-cycle programs performed a gradual verification of correctness of their decision-making (nearly for all the key experiences were those from practice). If a student was convinced that pedagogical studies and the work of educators were a source of their satisfaction, they usually profiled their understanding of studies towards the perception of their ability to develop their personality in the sphere of professional activity and expressed the will to acquire purely professional competence (thus towards the " $\mathrm{f}$ " profile: 06K1, $06 \mathrm{~K} 4$ or G: $06 \mathrm{~K} 8,06 \mathrm{~K} 9,06 \mathrm{~K} 7)$. If on the contrary, they experienced inadequacy of study choice and continued for ambition reasons (profile "I": 06K2) to get a diploma (profile " $k$ " J: 06K5).

Current graduates during undergraduate studies, as their colleagues did in the first stage of their studies a decade ago, profile their understanding of study orientated towards the value of personal development and acquiring social experience, remaining less patient on their path. From the first weeks of their stay at the university they test whether they have chosen correctly at any time being ready to change their decision and resign from their studies, move to another university or change specialization $(16 \mathrm{~K} 7,16 \mathrm{~K} 3,16 \mathrm{M} 2)$. Their choices of second-degree studies are much more well-thought but also more specifically focused on career development (all except 16K1 and 16K5). In fact, all 2016 interviewees agreed that they were taking second-degree studies expecting specialized tools for the planned and often performed pedagogical work. Pedagogical second-level studies are not linked to the broadly defined process of personality development but alongside the completion of education - obtaining a Master's degree, acquiring formal pedagogical/teacher qualifications (if they have not obtained them during first-degree studies).

A significant change in the understanding of personality development is still evident: the interviews of 2006 document that it was combined with their ability to check themselves in new conditions and take on interesting and attractive tasks, broadening their interests, developing passions, leading to self-discovery and reinforcement of self-identity (06K3, 06K4, 06M1, 06K7, 06K12). Interviewees of 2016 speak on personality development in terms of exploring new opportunities, trying something new and self-realization - as a stacking of functions and tasks that can be described in CV $(16 \mathrm{~K} 3,16 \mathrm{M} 6,16 \mathrm{M} 1,16 \mathrm{~K} 8)$. Young people engage in various activities, weighing their importance for their further careers, calculating whether making them de facto pays off. They invest in their development, maximizing work-related effort undertaken to gain experience and resources for "comfortable study". This mill of everyday life distances them from participation in culture, moments of personal silence, in-depth reflections. Personality strength begins to be measured as the level of vital fitness (fitness, resistance to fatigue, mental strength, resistance to stress) and not intellectual or development of reflexivity. 
3. Changes in the field designated by "work-profession category": aspirations for professional development or enhancing own competitiveness on the labour market?

Building the understanding of the importance of pedagogical studies in the context of the value of "professional work", frequent in the narratives of 2006, ten years later becomes dominant, so the first clear trend is to increase thinking about study as a way to prepare for professional career. Recently, there has been a preference for studies that give specific qualifications to professional work identified as accessible (obtainable) on labour market.

Statements made about future and, importantly, current professional work (students graduated from second-degree studies with a professional diploma work very often) is generally predominating in interviews. Professional activity may be a favourable circumstance for educational process since as the respondents indicate professional experience results in increased interest, in particular, in methodological (but not only) subjects and bigger involvement in classroom activities $(16 \mathrm{~K} 6,16 \mathrm{~K} 7,16 \mathrm{~K} 1)$. On the other hand, work results in lack of time for studies and also for student life and deepening of friendships, which probably does not remain without any significance to social and interpersonal sensitivity of young people.

Interviews, however, show that orientation to professional work under current conditions begins to manifest itself in the utilitarian, calculated and profit-driven nature of students' activities, both in their studies (starting parallel studies, studying two specializations, participation in various types of training motivated by credits granting and not by desire to develop knowledge or passion) as well as activities outside the studies (aimed at increasing their attractiveness on the labour market, establishing contacts with potential employers, expanding their portfolio).

4. Changes in the field designated by the category of "realization of formal actions": pursuit of higher educational success of higher level or desire to hold a diploma?

Young people undertaking studies in the context of their mass nature and nonselectivity see it as an obvious and natural way to continue education as an organized process of specific tasks and requirements, leading to obtaining a higher education diploma giving specific qualifications. Thinking by students about studying in categories focused on formal aspect is a description of the specific activities undertaken for the implementation of program duties. In this context, in 2006 and 2016 interviews, similar criticisms were made: the accumulation of theoretical subjects in the first years of study has been pointed out, the aforementioned over-saturation with the theory of general pedagogy, the expectation of practical knowledge connected with the chosen specialization, the value of practice and the need for their proper use have been emphasised, the irritation for repetitive content has been expressed, discouragement by boring way of conducting classes as well as satisfaction with workshop and training classes, examples of excellent academic didactics have been given

The students point to its different educational attainment in relation to school education, emphasizing its educational value: the development of responsibility and selfdiscipline but their 2006 statements alongside with the examples of freedom in the way they perform their program tasks (freedom of attending lectures, freedom from schoolgrading system, treating them as objects) very often indicated the importance of the ability to choose the knowledge held, chosen as valued and interesting (06M2, 06K10), which can be co-created $(06 \mathrm{M} 1)$, while criticizing that this knowledge chosen by students is still not enough (06M1, 06K3, 06K4, 06K2). In 2016, the problem of self-reliance and selfresponsibility for the learning process occurs only in the first context of the way of implementing program tasks $(16 \mathrm{~K} 3,16 \mathrm{~K} 7,16 \mathrm{M} 1)$.

IDI students are worried that many students fail to fulfil their duties and disregard their studies. They emphasize their disagreement with the practice of cheating on or 
copying assignments, even diploma papers and with the lack of their colleagues culture in daily functioning of the university, especially not being in line with the attitude of people who in future will be educators. It is noteworthy that these critical themes were taken by students graduating in 2016. In interviews in 2006, they appeared in the context of evaluating the behaviour of first-year colleagues. The students pointed to the gap separating them from their younger colleagues and have already expressed their concerns about academic culture and the level of future teaching staff $(06 \mathrm{~K} 11,06 \mathrm{~K} 12,06 \mathrm{~K} 5)$.

Contemporary students see in their studies a formal offer of something "for themselves" since obtaining education in their understanding remains open and available opportunity for them. The studies cease to be the only or the most important stage, rather natural and the first (to complete) to be able to pursue further plans, including educational ones (the obvious use of postgraduate studies, courses, studying new disciplines of science). Interviews document that, in the belief of the participants of the study, the diploma is supposed to confirm the meeting of the requirements of the program, it should be something deserved, hence the frequent words of dissatisfaction that someone gets it for nothing, that somewhere is easier, that generally on the market there are many. It seems, however, that the deflation of the value of diplomas observed today does not change the credit-related attitudes of the youths but on the contrary, only intensifies their efforts to accumulate bigger and bigger number of them.

\section{CONCLUSIONS}

In the light of the presented material it seems unfortunately that pedagogical studies, like any other (and perhaps even more than others), have ceased to be perceived by pragmatically orientated youth as an autotelic value -

acquiring knowledge that develops personality and makes them more knowledgeable and reflective, but as an educational investment that increases their attractiveness on the labour market and aims to prepare for a professional role. Neoliberal culture of consumption seems to liberate and consolidate such thinking and, contrary to the ever-present declarations of promotion of creativity and self-reliance, it strengthens adaptive attitudes. There is a serious danger that many of the new teachers and educators leaving the university will not be able to raise the education to a higher level.

Rather perspective we see further studies on the matter.

\section{REFERENCES}

1. Baudrillard, J. (2006). Consumer society. Its myths and structure. Warsaw: Sic Publishing House.

2. Bauman, Z. (1999). Identity. Then, now, for what? In E. Nowicka, M. Chałubiński (Eds.), Ideas and the organization of the social world (pp. 43-45). Warsaw: PWN Scientific Publishing House.

3. Bauman, Z. (2009). Consumption of life. Cracow: Jagiellonian University Publishing House.

4. Giddens, A. (2001). Modernity and identity. Me and society in the era of late modernity. Warsaw: PWN Scientific Publishing House.

5. Habermas, J. (1999). Theory of communicative action, volume I: rationality of action and social rationality. Warsaw: PWN Scientific Publishing House.

6. Jankowska, D. (2014). Efficiency/effectiveness of academic educationbetween pragmatism and fiction. In A. Karpińska, W. Wróblewska (Eds.), Academic didactics - selected research areas (pp. 82-96). Warsaw: Żak Academic Publishing House. 
7. Kautz, T. (2011). Overview of teacher education system in Poland in 19452010. Scientific journal of the Naval Academy, R. LII, 2 (185), 187-202.

8. Melosik, Z. (2004). Popular culture as a factor of socialization. In ed. Kwieciński, B. Śliwerski (Eds.), Pedagogy. Academic manual (part 2) (pp. 68-91). Warsaw: PWN Scientific Publishing House.

9. Rorty, R. (2000). Education and the challenge of postmodernity. In Z Kwieciński (Ed.), Alternatives of thinking on/for education (pp. 143-150). Warsaw: IBE Publishing House.

10. Rutkowiak, J. (2009). Dialogue and education projects for the contemporaries. In ed. E. Dąbrowa, D. Jankowska (Eds.), Pedagogy of dialogue. Dialogue in the theory and practice of education (pp. 14-28). Warsaw: Academy of Special Pedagogics Publishing House.

11. Włoch, S. (2005). In search of innovative teacher education. In Z. Andrzejak, L. Kacprzak, K. Pająk (Eds.), Polish education system after the reform of 1999. Status, prospects, threats (pp. 221-230). Poznań-Warsaw: Ellipse Publishing House.

12. Woźnicki, J. (Ed). (2008). The formula of two-stage and advanced studies. Warsaw: Polish Rectors' Foundation, Conference of Rectors of Polish Academic Schools. 